This is an electronic reprint of the original article. This reprint may differ from the original in pagination and typographic detail.

Author(s): Kettunen, Jaana; Sampson, James P.; Vuorinen, Raimo

Title: $\quad$ Career practitioners' conceptions of competency for social media in career services

Year: $\quad 2015$

Version:

Please cite the original version:

Kettunen, J., Sampson, J. P., \& Vuorinen, R. (2015). Career practitioners' conceptions of competency for social media in career services. British Journal of Guidance and Counselling, 43(1), 43-56. https://doi.org/10.1080/03069885.2014.939945

All material supplied via JYX is protected by copyright and other intellectual property rights, and duplication or sale of all or part of any of the repository collections is not permitted, except that material may be duplicated by you for your research use or educational purposes in electronic or print form. You must obtain permission for any other use. Electronic or print copies may not be offered, whether for sale or otherwise to anyone who is not an authorised user. 


\title{
Career Practitioners' Conceptions of Competency for Social Media in Career Services
}

\author{
Jaana Kettunen, James P. Sampson, Jr \& Raimo Vuorinen
}

\section{Jaana Kettunen ${ }^{1}$}

Finnish Institute for Educational Research

P.O. Box 35

40014 University of Jyväskylä, Finland

Tel. +358408054255

Email: jaana.h.kettunen@jyu.fi

Jaana Kettunen works as a researcher at the Finnish Institute for Educational Research of the University of Jyväskylä, Finland. Her current research focuses on social media in career services and aspects that are seen as critical in the successful use of these new technologies in career services.

\section{James P. Sampson, Jr}

Florida State University

P.O. Box 3064450

1114 West Call Street

Tallahassee, Florida 32306-4450

Tel. +1 8506446885

Email: jsampson@admin.fsu.edu

Dr Jim Sampson is the Mode L. Stone Distinguished Professor of Counseling and Career

Development in the Department of Educational Psychology and Learning Systems, Associate

Dean of the College of Education, and co-director of the Center for the Study of Technology in Counseling and Career Development, at Florida State University.

\section{Raimo Vuorinen}

Finnish Institute for Educational Research

P.O. Box 35

40014 University of Jyväskylä, Finland

Tel. +358 503611909

Email: raimo.vuorinen@jyu.fi

\footnotetext{
${ }^{1}$ Corresponding author: Jaana Kettunen Email: jaana.h.kettunen@jyu.fi
} 
Dr. Raimo Vuorinen is currently a senior researcher at the Finnish Institute for Educational Research in the University of Jyväskylä. His interest is on the strategic design and evaluation of lifelong guidance services and policies. In 2007-14 he has been the Co-ordinator of the European Lifelong guidance Policy Network, ELGPN. 


\section{Career Practitioners' Conceptions of Competency for Social Media in Career Services}

This article reports findings from a phenomenographic investigation into career practitioners' understanding of competency for social media in career services. Sixteen Danish and Finnish practitioners with experience using social media in career services were interviewed in focus groups. Competency for social media in career services was conceived as 1) an ability to use social media for delivering information, 2) an ability to use social media for delivering career services, 3) an ability to utilise social media for collaborative career exploration and 4) an ability to utilise social media for co-careering. The findings can be used to develop preservice and in-service training of career practitioners and support for the deepening of their competency, using the critical aspects that were identified.

Keywords: career services; career practitioners; competency; information and communication technology; phenomenography; social media

The exponentially increasing use of social media across the career service sector has placed an increasing demand upon career practitioners' ability to be innovative, take advantage,of and fashion novel career service delivery formats with online technologies (e.g. Hooley, Hutchinson, \& Watts, 2010a, 2010b; Watts, 2010). In career services, social media is fast becoming as much a necessity as an opportunity and competency to work in this new mode is an area of increasing importance. To many, social media is simply a collection of online tools used to share information, communicate, and socialise with one another. In the broader sense, social media is defined as a process in which individuals and groups develop common understandings and meanings with contents, communities, and Web 2.0 technology (e.g. Ahlqvist, Bäck, Heinonen, \& Halonen, 2010; Kolbitsch, \& Maurer, 2006). Thus, it primarily refers not to a particular 
set of technologies but to types of practices (Bonderup, \& Dohn, 2009). In order to consider the usefulness and potential of existing and emerging technologies, it is essential that career practitioners be appropriately trained in this area (e.g. Bimrose, Hughes, \& Barnes, 2011; Osborne, Dikel, \& Sampson, 2011, Watts, 2010). There is an urgent need for competency training to be firmly grounded in a framework of career practice and for an emphasis to be placed on adopting a more developmental approach to capacity building (Bimrose, Barnes, \& Atwell, 2010). It is also very likely that practitioners working in this area need to be trained differently than for the traditional face-to-face service mode (Niles, \& Harris-Bowlsbey, 2013).

Considerable research has been conducted to identify the skills and competencies that practitioners require in order to use existing and emerging technologies in career services (e.g. Barnes \& Watts, 2009; Barnes, La Gro, \& Watts, 2010; Bimrose et al., 2010; Cogoi, 2005; CEDEFOP, 2009; Pyle, 2000). Careful consideration has also been given to ethical issues related to the use of technologies in career practice (e.g. Barak, 2003; Malone, 2007; Sampson, 2002, Sampson \& Makela, 2014). According to Pyle (2000), the competencies needed for career practitioners using information and communications technology (ICT) in career service delivery include knowledge of computer-assisted software and websites, the ability to diagnose client needs, the ability to motivate clients, the ability to help clients process data and the ability to help clients create and implement an action plan. Cogoi (2005) identified three purposes for ICT in guidance, each of which might require practitioners to develop specialised/specific competences: as a resource, as a medium for communication and for material development. More recently, Barnes and Watts (2009) mapped ICT-related competences for guidance practitioners under two broad units: competence for using ICT to deliver guidance and competence for developing and managing the use of ICT in 
guidance. The first set of competences is comprised of using ICT to deliver guidance to meet clients’ information needs, experiential learning needs, constructivist learning needs and communication needs. The second set of competences is comprised of not only developing the use of ICT-related guidance solutions, but also managing the use of ICT-related solutions in a service context. Bimrose et al. (2010) emphasised that the skills and competences required for Internet-based career guidance need to be regarded as two separate but inter-related domains. One domain relates to the career

practitioners' ICT user skills and competencies, while the other relates to more generic career guidance skills and competencies.

Recent studies have revealed that in career services, the models of career intervention and ways of experiencing and conceptualising social media appear to be intertwined (Kettunen, Vuorinen, \& Sampson, 2013, in press). The findings indicate that if career field social media is to play an increasing role in career services, it is necessary to expand career practitioners' awareness of the varying models of career interventions with online technologies. However, no research has specifically analysed career practitioners' conceptions of competency for social media in career services.

Throughout this article, the term competency will be used to refer to a combination of the relevant attributes that underlie the aspects of successful professional performance (Moore, Cheng, \& Dainty, 2002).

\section{Aim and Research Questions}

This phenomenographic study sought to examine the conceptions of competency for social media among career practitioners who have experience in using social media for career services. The main aim is to discover and describe the qualitatively different ways in which practitioners understand competency for social media in career services. The key research questions are as follows: (1) What are the career practitioners' 
conceptions of competency for social media in career services? (2) What are the critical aspects that differentiate qualitatively varying ways of understanding competency for social media? The ultimate aim of describing the variation is to expand the career practitioners and trainers understanding of critical aspects in the development and successful use of existing and emerging technologies in career services. The results may support and provide an impetus for the development of pre-service and in-service training of career practitioners while also contributing towards quality assurance in training.

\section{Methods}

This study examined the career practitioners' conceptions of competency for social media in career services using a phenomenographic approach (Åkerlind, 2005b, 2012; Marton 1981, 1986; Marton \& Booth, 1997; Marton \& Pong, 2005). Phenomenography is a qualitative research approach that seeks to explore variations in how people experience or understand a particular phenomenon. The primary outcome of a phenomenographic analysis is a hierarchically structured set of logically related categories that describe, on a collective level, people's qualitatively different ways of experiencing or conceptualising the phenomenon in question (Marton, 1986). Marton and Booth (1997) emphasised that the categories of description should meet the following three quality criteria: each category should describe a distinctly different way of experiencing the phenomenon; a logical relationship between each category should be hierarchically represented; and there should be a limited, parsimonious number of different categories that describe the variation across the sample. The process used to ensure quality descriptions in this study is described in the data analysis section. 


\section{Participants and the Context of the Study}

The participants in this study were sixteen Danish and Finnish career practitioners with experience using social media in career services. Seven of the sixteen participants were from Denmark and nine were from Finland. There were ten females and six males, who represented the age range from 30 to 59 and whose career service experience range from 2 to 17 years. In keeping with phenomenographic techniques (Åkerlind, Bowden, \& Green, 2005; Marton \& Booth, 1997), variation within the participants was deliberately sought out in order to yield as much variation as possible in the understandings of competency for social media in career services. Emails inviting practitioners with experience using social media were sent to a variety of Finnish professional guidance bodies and training units. An email was also sent to eVejledning, a national eGuidance center in Denmark that provides services via various virtual communication channels and social media settings. Experiences concerning the use of social media guided the identification and selection of the interviewees, and purposive sampling (Patton, 2002) was used to ensure the use of information-rich cases with the potential to produce significant amounts of data relevant to the research investigation. In previous phenomenographic studies, it has been suggested that as long as the sample is selected so as to maximize variation, between 10 to 15 subjects is normally sufficient to capture the variation (Åkerlind, 2008; Trigwell, 2000). The study participants represent the guidance community from a variety of settings, including comprehensive, secondary and higher education, as well as public employment services in both urban and rural settings.

\section{Data Collection}

The data for the study were gathered using the focus group interview methodology 
(Bogdan \& Biklen, 2006; Kitzinger \& Barbour, 1999; Krueger, 1997a, 1997b, 1998).

Because the aim of this study was to investigate a range of understandings of the same phenomenon, focus groups were considered an effective method for encouraging the participants to express their thoughts and experiences through interacting with each other. Furthermore, focus groups were considered appropriate because phenomenographic research aims to capture collective rather than individual accounts of people’s experience and understanding of the phenomenon under study.

Three focus groups, one in English with Danish career practitioners and two in Finnish with Finnish career practitioners, were conducted between February and May 2012. The focus group interviews were semi-structured and consisted of questions designed to direct the interviewees' focus towards the target phenomenon. The following five questions were asked: "What is the role of the career practitioner in meeting career services goals?”, "What is the role of social media in career services?”, “What is career service like in social media?”, "What are the skills needed for social media in career services?”, and “How can social media be best utilised in career services?”. The interviews were informal and conversational, allowing the interviewees to discuss their current understandings of and experiences with the phenomenon as fully and openly as possible. Neutral follow-up questions were used to encourage the participants to elaborate on or clarify their responses, examples of which include the following: “Could you tell a bit more about that?”, “Could you describe it/explain it a little further?” and “Could you give an example of it?” were used to encourage the participants to elaborate on or clarify their responses. When asking follow-up questions, the facilitator was careful to avoid leading the practitioners' responses. Digital recordings of the focus group interviews were transcribed verbatim for analysis. 


\section{Data analysis}

Phenomenographic data analysis strategies vary (Åkerlind, 2005b, 2012). Bowden (1995, 2000b) has advocated for transcript analysis, whereas Marton $(1986,1994)$ has utilised segments from transcripts and preferred to explore smaller section analysis. The approach taken in this study followed the guidelines and examples offered by Marton (1986), Bowden (2000a), Bowden and Green (2010) and Åkerlind (2005a,b) and sought to consider the transcripts as a whole. The purpose of using the entire transcripts or large sections of each transcript was to increase the accuracy of the interpretation of the answers (Åkerlind et al., 2005).

The first phase of the analysis focused on identifying and describing the career practitioners’ ways of understanding competency for social media in general terms. Repeated reading afforded greater familiarisation with the data, and by focusing on the similarities and differences in the expressed meanings cases of variation or agreement were identified and grouped accordingly. Gradually, by comparing similarities and contrasting differences, a draft set of descriptive categories for collective meanings was developed, defined and named.

The second phase of the analysis focused on delineating the logical relationships and the structure between the various categories. Common themes of variation in the career practitioners' ways of understanding competency for social media were identified and used to structure the logical relationships both within and between the categories (Åkerlind, 2005a). The aim was to reveal variation among the key aspects in terms of how one way of seeing a phenomenon differs from another, more complex one (Åkerlind, 2005a; Marton \& Booth, 1997).

To ensure a robust analysis of the interview data, the data were first analysed by the first author, and then, a second opinion was sought from research colleagues with 
whom the first author met several times in order to discuss and revise the categories and their structures. This was done in an attempt to ensure that each category would confirm the validity of the interpretations of the data. Iterative re-reading and re-drafting continued until saturation occurred, that is, until the re-reading no longer produced any significant change in the categories of description (Bowden \& Green, 2010).

\section{Results}

The analysis of the data revealed four distinct categories of description reflecting the career practitioners’ conceptions of competency for social media in career services (Table 1). Each category adds to or deepens the previous category. Competency for social media in career services was conceived as 1) an ability to use social media for delivering information, 2) an ability to use social media for delivering career services, 3) an ability to utilise social media for collaborative career exploration and 4) an ability to utilise social media for co-careering. The formed categories were nested in hierarchies expanding from the least understanding to the most complex understanding. The phenomenal aspects differentiating the categories are known as dimensions of variation. They comprise the critical aspects for expanding a more sophisticated or complete level of understanding. These dimensions were named: approach to social media, function of social media in career services, online skills, ethical principles and personal characteristics.

Table 1. Career practitioners' conceptions of competency for social media in career services

File1

Each category is described in more detail below. Excerpts from relevant interview transcripts are included to illustrate the key aspects of each category. It should 
be noted that this categorisation represents collective conceptions of competency rather than individual conceptions of competency for social media in career services. Thus, at an individual level, some practitioners hold more than one conception of a given phenomenon.

\section{Description of the Categories}

Category 1: Competency for social media in career services is an ability to use social media for delivering information

In the first category, competency for social media is conceived as an ability to use social media for delivering information. The practitioners' approach to social media is technology focused, meaning that emphasis is placed on the operational understanding of various social media tools and ways of using these tools as a means for delivering information.

"We have to know how social media tools, sharing and "likes” work. I am talking about Facebook, but also Google+ and the other ones.”

Practitioners regard media literacy as a key online skill for social media use. In this category, they emphasise that the ability to be an active and safe participants in social media requires proficiency in locating, evaluating and using various types of online content and services in a critical and active manner. Furthermore, the ability to support individuals in this area is highlighted.

"Because career practitioners need to obtain an awful lot of timely information, I’d say that having good media literacy is kind of like general knowledge, all-around education.”

"You can find so much information from the Internet, but if you don’t know which of them to pick from, then you'll just be lost.” 
Practitioners express ethical concerns about the accuracy and validity of information, especially with respect to the information they present and share online. Practitioners anticipate that their professionalism is more easily questioned or challenged in open social media settings and they highlight the importance of the professional tone and accuracy of information.

"You have to balance with making good posts and being right all the time."

"I asked some of my colleagues before I posted it; yes, I had to feel sure that it was all right.”

Personal motivation is considered to be a key factor for adaptation and participation in social media. Practitioners state that interest in experiencing and participating in social media is essential in order to learn what does and what does not work in social media settings.

"Technical know-how, it is not a threshold question...I mean that if there is motivation, for sure one will manage.”

Category 2: Competency for social media in career services is an ability to use social media for delivering career services

In the second category, competency for social media is conceived as an ability to use social media for delivering career services. The approach to social media is now content focused, meaning that emphasis is placed on content-centred communication and ways of using social media not just for delivering information but also as a medium for oneto-one communication.

"It is not the [social media] technology that is the main role; I mean that we should be using it in such a way that the content rises in the focus." 
Practitioners regard online writing as being a key skill for social media use.

They emphasise that the ability to be a versatile writer and develop a style that meets the needs of the individuals they are trying to reach or serve requires various types of writing skills and a readiness to do things in new ways. Furthermore, thoughtful and careful word usage is highlighted because the interpretation of the meaning, intent and tone might rely solely on the typed words.

\footnotetext{
"In terms of online writings skills, I mean that you must be able to write with such a language in there [social media] that you will be taken seriously. Literary language may not quite be the thing.”

“"'The power of [typed] words and the attitudes that come across there [social media] such as the choice of words, do I call myself 'unemployed' or am I 'between jobs?' Oh, well, I do reflect upon these things.”
}

In this category, practitioners ethical concerns extended from the accuracy and validity of information to privacy issues in social media. Practitioners are especially concerned with ensuring that communication with individuals is protected to the degree they desire. The importance of understanding the privacy provisions and privacy settings of various social media tools is highlighted. Additional concerns exist regarding the line between personal and professional lives, which might get blurred in social media settings.

\footnotetext{
"You have to also be aware of the risks, like the issues that we discuss with individuals, with students, they are very private and if that would go public, I mean, it could do a lot of harm.”
}

Practitioners express that the implementation of social media is an ongoing process that requires not only motivation but also patience and perseverance. Experimenting with and integrating social media is a step-by-step process, and it takes 
time to establish a positive awareness before individuals find and engage with career services.

“Conducting career services in social media requires patience.”

"One has to understand that it is not sealed and delivered at once but continues to evolve over time.”

Category 3: Competency for social media in career services is an ability to utilise social media for collaborative career exploration

In this third category, competency for social media is conceived as an ability to utilise social media for collaborative career exploration. The practitioners' approach to social media is pedagogically focused, meaning that emphasis is placed on the methods, techniques and activities that foster collaborative processes in career learning among peer group members. While in the previous categories social media functioned merely as an alternative channel, here practitioners perceive social media as an interactive working space and an integral part of career services.

"You need to be able to break the content into smaller segments and it is about making it a process, and then individuals can create content and contribute.”

"And at its best we are able to get the students to reflect on their own views and by doing so they become producers of information themselves."

"So, if you are good at this, you'll have the capability to make something so interesting that other people will like to share it: the questions or the answers.”

Practitioners in this category regard online discourse as being a key skill for social media use. They emphasise that the ability to generate and maintain an engaging and constructive online discussion with individuals and groups requires appropriate structuring and active facilitation in terms of guiding and shaping the discourse. 
Furthermore, the practical understanding of the methods for enhancing participation and interaction in online discourse are highlighted.

"To my mind, skills for online discourse and know-how for the interpretation of the online discussions are also strongly needed.”

"You don’t feed facts. You ask questions. So, actually, we should be very good at doing social media."

Practitioners have ethical concerns related to confidentiality. The importance of preserving confidentiality while creating maximum value from the utilisation of social media is highlighted. Especially when working with a group, emphasis is placed on ensuring that participants understand and respect the confidentiality of the other group members.

"You must be able to build a certain level of confidentiality so that they dare to share their thoughts. It seems to me kind of like a key factor at the start or otherwise the group won't function so well.”

Practitioners state that establishing a presence and voice in social media requires personal confidence. The willingness to throw oneself into an open social media space, share information, and participate in online discourse takes courage.

\footnotetext{
"You need confidence to do things in social media."

"You need courage. It is important. Your counselling competence can be questioned at any time. That's new."
}

Category 4: Competency for social media in career services is an ability to utilise social media for co-careering

In this fourth category, competency for social media is conceived as an ability to utilise 
social media for co-careering where shared expertise and meaningful co-construction on career issues takes place with and among community members. The practitioners approach to social media is systemically focused, meaning that emphasis is placed on rethinking the organisational culture of career services, as well as the ideology and methods of practise and training. Unlike in previous categories, social media now functions as an impetus for paradigm change and reform in career services.

\footnotetext{
“This is also changing the rules: career services can’t make social media behave as career services would like it to. Instead, career services have to change the way career services works so that it will work through social media. That is a big challenge because we have to rethink the whole idea of career services.”
}

Practitioners regard online presence as being a key factor and skill for social media use. They emphasise that the ability to project oneself as reliable and real in communities where shared expertise and meaningful co-construction regarding career issues are present requires a cognisant, properly managed and monitored online presence. Furthermore, the practical understanding of methods and strategies for enhancing the sense of being with others and being present via an online medium is highlighted.

"I think that in social media you have to put in significantly more effort to be present and 'switched-on' than in live meetings."

"And presence in social media, it has to do with understanding how to behave there in such a way that you are treated as an equal and reliable.”

In this category, practitioners ethical reflections and concerns moved from privacy and confidentially issues to professional proficiency in open social media settings. Practitioners highlight the importance of ensuring that work-related activities in open social media settings come across as professional. The emphasis is placed on 
well-structured and well-thought-out professional goals and strategies that fit those goals.

"I perceive that part of professionalism is that before you go there [social media] you know what you are and what you want to bring out through this forum.”

Practitioners state that the utilisation of social media requires an innovative approach. Due to the collaborative and social nature of social media, practitioners must reframe their practice and both invent and design new ways of doing things.

"We need to create a completely new way of thinking in there [social media]..."

\section{Relationship Between the Categories}

The categories of description were distinguished from each other and organised hierarchically through dimensions of variation that emerged from the data. Due to the structural hierarchy of inclusiveness, some conceptions can be seen as more complete and more complex than others (Åkerlind, 2005a).

The career practitioners' approach to social media changed across the categories of description. In category 1, where competency for social media is conceived of as an ability to use it for delivering information, the distinct difference in relation to other categories was the technology focused approach to social media. A shift from technology to a content focused approach was discerned in category 2, where competency for social media is conceived as an ability to use it for delivering career services. A turning point occurred in category 3. This marked a change in approach as the emphasis shifted from being mainly technology focused and content focused to being pedagogically focused. In the most complex category, where competency for social media is conceived as an ability to utilise it for co-careering, a shift to a systemically focused approach was discerned. 
In terms of the function of social media in career services, the transition across the categories was from the means for delivering information to an impetus for paradigm change and reform. The most distinct difference between category 1 and the other categories was that social media functioned merely as a means for delivering information, while in the more complex categories, the viability of social media as an alternative communication channel and working space was also emphasised. A change from emphasising the information transmission function to viewing social media as a medium for one-to-one communication was discerned in category 2, where competency for social media is conceived as an ability to use it for delivering career services. A turning point was again seen in category 3, as it marked a shift in the function of social media from being an alternative information and communication channel to being an interactive working space. A significant shift where social media began to function as an impetus for paradigm change and reform in career services was discerned in category 4, where competency for social media is regarded as an ability to utilise it for co-careering.

Shifts in online skills appeared as transitions from media literacy to an online presence. In category 1, media literacy, the ability to locate, evaluate and use various types of online content and services in a critical and active manner was considered to be a prerequisite skill for social media activity, whereas in category 2, versatile online writing skills with a style that meets the individuals' needs were emphasised since the interpretation of the meaning, intent and tone may rely solely on the typed words. In category 3, where competency for social media is conceived as an ability to utilise it for collaborative career exploration, online skills are extended to participating in online discourse, which requires appropriate structuring and active facilitation in terms of guiding and shaping constructive discourse. In the most complex category, the emphasis was placed on online presence skills. 
Ethical principles regarding the use of social media varied across the categories. In category 1 , where competency for social media is conceived as an ability to use it for delivering information, the ethical concerns relate to accuracy and validity in obtaining and sharing information online. In categories 2 and category 3, where competency for social media is regarded as an ability to use it for delivering career services and collaborative career exploration, the ethical concerns shifted to privacy (category 2) and confidentiality (category 3) issues in social media. In the most complex category, ethical reflections and concerns moved to those regarding professional proficiency in open social media settings.

The personal characteristics of practitioners who work with and in social media were characterised differently in all categories. In the least complex categories, the identifiable characteristics were motivation (category 1) and patience (category 2). Being confident was defined as a key characteristic in category 3, where competency for social media is conceived as an ability to utilise it for collaborative career exploration. In the most complex category, where competency for social media is conceived as an ability to utilise it for co-careering, innovative behaviours and characteristics were emphasised.

\section{Discussion}

This study identified career practitioners' different ways of understanding competency for social media in career services in four distinct categories of description that ranged from an ability to use social media for delivering information to an ability to utilise social media for co-careering where shared expertise and meaningful co-construction on career issues takes place with and among community members. Five dimensions of variation were identified: approach to social media, function of social media in career services, online skills, ethical principles and personal characteristics. 
The findings show similarities with earlier studies on competencies required by career practitioners to use information and communications technology in career services; however, this study's results also provide some new insights into those discussions. The main similarities with earlier studies (e.g. Barnes \& Watts, 2009) can be found in the results from the first three categories, where the conceptions of competency for social media in career services include the ability to deliver information and career services, as well as collaborative career exploration. That finding is also in accordance with Cogoi’s (2005) earlier observation that guidance practitioners may require competences for using ICT as a resource, as a medium for communication and for material development. The most complex category in this study revealed an additional competency, an ability to utilise social media for co-careering, which has not previously been discussed. In this category, the systemically focused approach to social media was first articulated; social media became an impetus for paradigm change and reform, and the emphasis was placed on methods and strategies for creating a cognisant, properly managed and monitored online presence. The findings also further support the observations regarding ethical issues related to the use of technologies in career practice (e.g. Sampson \& Makela, 2014) and Bimrose et al.’s (2010) notion that the career practitioners' ICT user skills and competencies, as well as their more generic career guidance skills and competencies, need to be regarded as two separate but inter-related domains.

The findings of this study show that competency for social media in career services is not only about a particular set of new skills. Success in developing competency for social media in career services is a dynamic combination of cognitive, social, emotional and ethical factors that are interwoven. On the basis of our findings, we argue that it is important to develop pre-service and in-service training of career 
practitioners and support for deepening their competency for social media by using the critical aspects identified in this study. There is an urgent need for both the pre-service and in-service training curricula to be updated to include this knowledge. Career practitioners and trainers should recognise the variety that exists in understanding competency for social media in career services and they should understand the critical differences between their current conceptions and the more advanced ways of conceptualising competency that they can potentially move towards. A major task in training is to bring about learning experiences that provide practitioners with the opportunity to discern the critical aspects needed for expanding both their practical and conceptual understandings of competency in the use of social media. The hierarchical structure of the findings can serve as a pedagogical tool for trainers of career practitioners, enabling them to ground and convert these new competences in the future practice and continuous development in it. This is crucial if career practitioners are to successfully adjust to the paradigm shift in career services that is emerging along with the current use of social media (Kettunen et al., in press). This topic, like the reaffirmation or revision of the role of guidance, is needed within training. Further research and experimentation regarding the pedagogical use of the results are needed. 


\section{References}

Ahlqvist, T., Bäck, A., Heinonen, S., \& Halonen, M. (2010). Road-mapping the societal transformation potential of social media. Foresight, 12(5), 3-26. doi: $10.1108 / 14636681011075687$

Åkerlind, G. (2005a). Learning about phenomenography: Interviewing, data analysis and qualitative research paradigm. In J. A. Bowden \& P. Green (Eds.), Doing developmental phenomenography (pp. 63-73). Melbourne: RMIT University Press.

Åkerlind, G. S. (2005b). Variation and commonality in phenomenographic research methods. Higher Education Research \& Development, 24, 321-334. doi:10.1080/07294360500284672

Åkerlind, G. S. (2008). Growing and developing as a university teacher. Higher Education, 55, 241-254. doi:10.1007/s10734-007-9052-х

Åkerlind, G. S. (2012). Variation and commonality in phenomenographic research methods. Higher Education Research \& Development, 31, 115-127. doi:10.1080/07294360.2011.642845

Åkerlind, G., Bowden, J. A., \& Green, P. (2005). Learning to do Phenomenography: A reflective discussion. In J. A. Bowden \& P. Green (Eds.), Doing developmental Phenomenography (pp. 74-100). Melbourne: RMIT University Press.

Barak, A. (2003). Ethical and professional issues in career assessment on the Internet. Journal of Career Assessment, 11, 3-21. doi:10.1177/106907202237457

Barnes, A., \& Watts, A.G. (2009). The conceptual framework - New map and new tools. In ICT Skills 2: ICT tools and training for e-guidance practitioners. Bologna: ASTER Scienza Tecnologia Impresa S. Cons p.a. 
Barnes, A., La Gro, N., \& Watts, A. G. (2010). Developing e-guidance competencies: The outcomes of a two-year European project to transform the professional development of career guidance practitioners. Career Research and Development: The NICEC Journal, 25, 26-32.

Bimrose, J., Barnes, S.-A., \& Atwell, G. (2010). An investigation into the skills needed by Connexions personal advisers to develop internet-based guidance. Reading: CfBT Education Trust.

Bimrose, J., Hughes, D., \& Barnes, S.-A. (2011). Integrating new technologies into careers practice: Extending the knowledge base. London: UK Commission for Employment and Skills.

Bogdan, R. C. \& Biklen, S. K. (2006). Qualitative research for education: An introduction to theories and methods (5th ed.). Boston: Allyn \& Bacon.

Bowden, J. (1995). Phenomenographic research: Some methodological issues. Nordisk Pedagogik, 15, 144-155.

Bowden, J. (2000a). Experience of phenomenographic research. A personal account. In J. Bowden \& E. Walsh (Eds.), Phenomenography (pp. 47-61). Melbourne: Royal Melbourne Institute of Technology.

Bowden, J. (2000b). The nature of phenomenographic research. In J. Bowden \& E. Walsh (Eds.), Phenomenography (pp. 1-18). Melbourne: Royal Melbourne Institute of Technology.

Bowden, J. A. \& Green, P. J. (2010). Relationality and the myth of objectivity in research involving human participants. In J. Higgs, N. Cherry, R. Macklin, \& R. Ajjawi (Eds.), Researching practice - A discourse on qualitative methodologies (pp. 105-121). Rotterdam: Sense Publishers. 
Bonderup Dohn, N. (2009). Web 2.0: Inherent tensions and evident challenges for education. International Journal of Computer Supported Collaborative Learning, 4, 343-363.

Cogoi, C. (Ed.) (2005). Using ICT in guidance: Practitioner competences and training. Report of an EC Leonardo project on ICT skills for guidance counselors. Bologna: Outline Edizione.

CEDEFOP (2009). Professionalising career guidance: Practitioner competences and qualification routes in Europe. Cedefop panorama series 164. Luxembourg: Publications Office of the European Union.

Hooley, T., Hutchinson, J., \& Watts, A. G. (2010a). Careering through the web. The potential of Web 2.0 and 3.0 technologies for career development and career support services. London: UK Commission for Employment and Skills.

Hooley, T., Hutchinson, J., \& Watts, A. G. (2010b). Enhancing choice? The role of technology in the career support market. London: UK Commission for Employment and Skills.

Kettunen, J., Vuorinen, R., \& Sampson, J. P., Jr. (2013). Career practitioners' conceptions of social media in career services. British Journal of Guidance \& Counselling, 41, 301-317. doi:10.1080/03069885.2013.781572

Kettunen, J., Vuorinen, R., \& Sampson, J. P., Jr. (in press). Practitioners experiences of social media in career services.

Kitzinger,. J. \& Barbour, R. S. (1999). Introduction: the challenges and promise of focus groups. In R. S. Barbour and J. Kitzinger (Eds.), Developing focus group research (pp. 1-20). London: Sage.

Kolbitsch, J., \& Maurer, H. (2006). The transformation of the web: How emerging communities shape the information we consume. Journal of Universal Computer Science, 12, 187-213. 
Krueger, R. A. (1997a). Developing questions for focus groups: Focus group kit 3. Thousand Oaks, CA: Sage.

Krueger, R. A. (1997b). Moderating focus groups: Focus group kit 4. Thousand Oaks, CA: Sage.

Krueger, R. A. (1998). Analyzing \& reporting focus group results: Focus group kit 6. Thousand Oaks, CA: Sage.

Malone, J. F. (2007). Ethical guidelines, legal and regulatory issues in distance counseling. In J. F. Malone, R. M. Miller, \& G. R. Walz, (Eds.). Distance counseling: Expanding the counselor's reach and impact (pp. 133-148). Ann Arbor, MI: Counseling Outfitters.

Marton, F. (1981). Phenomenography: Describing conceptions of the world around us. Instructional Science, 10, 177-200.

Marton, F. (1986). Phenomenography - A research approach investigating different understandings of reality. Journal of Thought, 21, 28-49.

Marton, F. (1994). Phenomenography. In T. Husén, and T.N. Postlethwaite (Eds) The international encyclopedia of education, 2nd edition (pp. 4424-4429).Oxford: Pergamon Press.

Marton, F. \& Booth, S. (1997). Learning and awareness. Mahwah, NJ: Lawrence Erlbaum Associates, Publishers.

Marton, F. \& Pong, Y. W. (2005). On the unit of description in phenomenography. Higher Education Research \& Development, 24, 335-348. doi:10.1080/07294360500284706 
Moore, D. R., Cheng, M-I. \& Dainty, A. R. J. (2002). Competence, competency and competencies: Performance assessment in organisations. Work Study, 51, 314319.

Niles, S. G. \& Harris-Bowlsbey, J. (2013). Career development interventions in the $21^{\text {st }}$ century $\left(4^{\text {th }}\right.$ ed.). Boston, MA: Pearson.

Osborn, D. S., Dikel, M. R., \& Sampson, J. P. (2011). The internet: A tool for career planning ( $3^{\text {rd }}$ ed.). Broken Arrow, OK: National Career Development Association.

Patton, M. Q. (2002). Qualitative research \& evaluation methods ( $3^{\text {rd }}$ ed.). Thousand Oaks: Sage Publications.

Pyle, K.R. (2000). Career counseling in an information age: The promise of "High touch" in a "High tech" age. Career Planning and Adult Development Journal, 16(3), 7-29.

Sampson, J.P., Jr. (2002). Quality and ethics in internet -based guidance. International Journal for Educational and Vocational Guidance, 2, 157-171.

Sampson, J.P., Jr. \& Makela, J. P. (2014). Ethical issues associated with information and communication technology in guidance. International Journal for Educational and Vocational Guidance, 1, 135-148. doi:10.1007/s10775-0139258-7

Trigwell, K. (2000). A phenomenographic interview on phenomenography. In J. A. Bowden \& E. Walsh (Eds.), Phenomenography (pp. 62-82). Melbourne: RMIT University Press.

Watts, A. G. (2010). Policy issues relating to the use of ICT in lifelong guidance. Career Research and Development: The NICEC Journal, 25, 33-39. 